\title{
Asystole-induced Bradycardia by Dexmedetomidine during Endoscopic Submucosal Dissection
}

\author{
Tomoaki Yamasaki, Yuhei Sakata, Takehisa Suekane and Hiroko Nebiki
}

\begin{abstract}
:
Although dexmedetomidine (DEX) is a widely used analgesic and sedative agent for endoscopic procedures, cardiovascular complications, such as bradycardia and hypotension, are frequently experienced. We herein report the first case of asystole-induced bradycardia due to DEX during endoscopic submucosal dissection (ESD). An 81-year-old man without cardiovascular diseases was referred for gastric carcinoma. ESD was started after administering a loading dose of DEX followed by a continuous maintenance infusion of DEX. The patient's heart rate gradually decreased, and then cardiac arrest occurred. DEX has a risk of cardiac arrest, so bradycardia should not be underestimated during sedation with DEX.
\end{abstract}

Key words: asystole, adverse event, bradycardia, dexmedetomidine, endoscopic submucosal dissection, sedation

(Intern Med Advance Publication)

(DOI: 10.2169/internalmedicine.8813-21)

\section{Introduction}

Endoscopic procedures, such as endoscopic submucosal dissection (ESD), endoscopic retrograde cholangiopancreatography, or interventional endoscopic ultrasonography, are becoming increasingly complicated and require a prolonged time to complete. Conscious sedation is therefore necessary to reduce the pain and discomfort to patients and facilitate the procedure.

Dexmedetomidine (DEX) is widely used as an analgesic and sedative agent in surgeries, intensive care, and treatments without intubation (1). Although one of the benefits of this agent is its minimal respiratory effect, cardiovascular complications, such as bradycardia and hypotension, are frequently experienced, with reported rates of $14.2-42.4 \%$ and 20.6-56.1\%, respectively $(2,3)$.

We herein report the first case of asystole induced bradycardia due to DEX during ESD.

\section{Case Report}

An 81-year-old man was referred to our hospital for the treatment of a gastric carcinoma in the lower gastric body.
The size of the lesion was $20 \mathrm{~mm}$, and endoscopic ultrasonography revealed the lesion to be an intramucosal tumor. Thus, ESD was scheduled as treatment. He had a medical history of tongue carcinoma, diagnosed at 71 years old, for which he underwent surgery. He was not taking any regular medications at the time of admission and had no history of cardiovascular disease. His electrocardiogram (ECG) was normal (Fig. 2a), and his body weight was $55 \mathrm{~kg}$ before ESD. His blood pressure and heart rate (HR) were 134/63 $\mathrm{mmHg}$ and 60 beats per minute (bpm), respectively, at the beginning of ESD.

DEX was administered intravenously at $5.8 \mu \mathrm{g} / \mathrm{kg} / \mathrm{h}$ for $10 \mathrm{~min}$ as a loading dose. As premedications, midazolam and pentazocine were injected at 2 and $7.5 \mathrm{mg}$, respectively, at the beginning of the procedure. ESD was initiated with DEX at $0.58 \mu \mathrm{g} / \mathrm{kg} / \mathrm{h}$ as a maintenance dose after loading. One minute after starting the maintenance dose, the patient's HR dropped to $48 \mathrm{bpm}$, so the infusion rate of DEX was decreased to $0.36 \mu \mathrm{g} / \mathrm{kg} / \mathrm{h}$. Since the HR did not improve, the infusion rate of DEX was further decreased to $0.07 \mu \mathrm{g} /$ $\mathrm{kg} / \mathrm{h}$. Marking and submucosal injection were performed as usual. When circumference cutting was initiated at 6 minutes after starting the maintenance dose, the HR decreased further to about $30 \mathrm{bpm}$, after which DEX infusion was

Department of Gastroenterology, Osaka City General Hospital, Japan

Received: October 12, 2021; Accepted: December 14, 2021; Advance Publication by J-STAGE: February 1, 2022

Correspondence to Dr. Tomoaki Yamasaki, tomorrow_aaa@yahoo.co.jp 


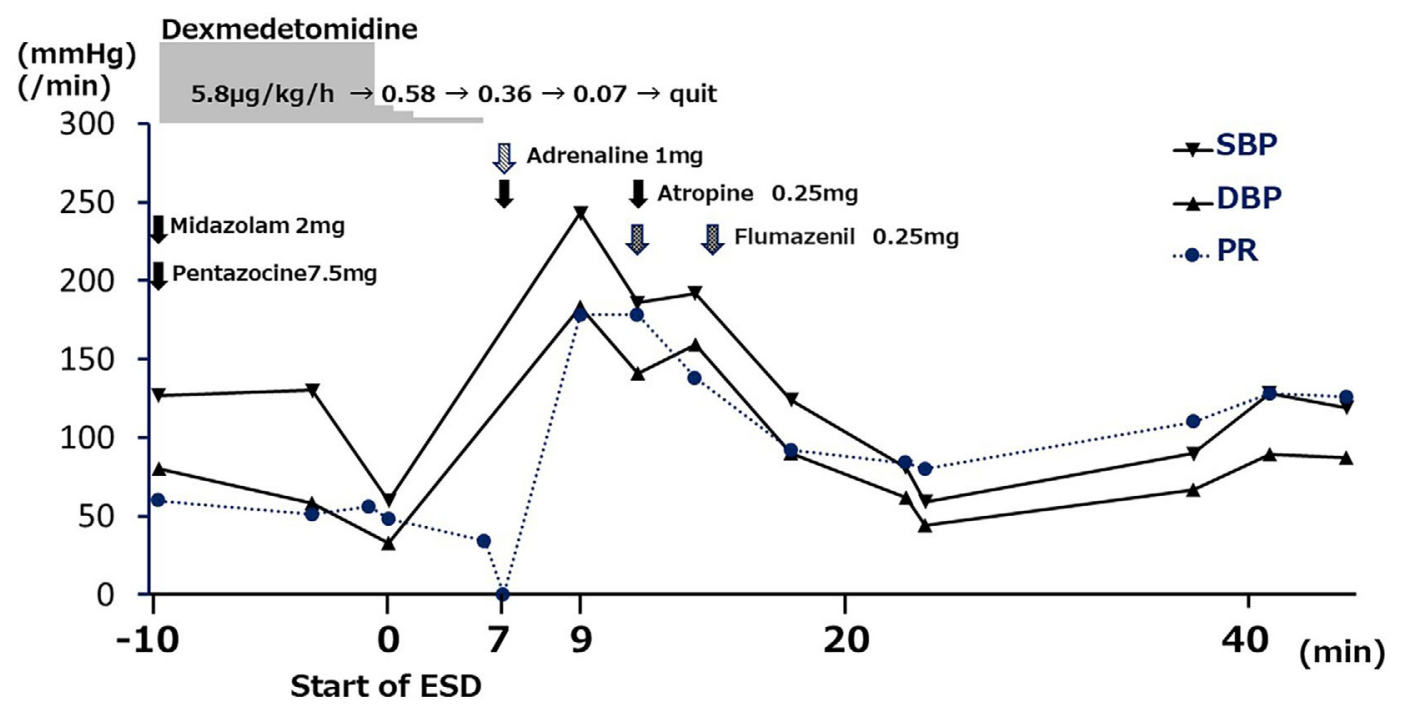

Figure 1. Time courses in endoscopic submucosal dissection. SBP: systolic blood pressure, DBP: diastolic blood pressure, PR: pulse rates

stopped. Cardiac arrest with asystole occurred one minute after stopping DEX, when one-third of the circumference had been cut, during the preparation of atropine. The endoscope was pulled out immediately, and cardiopulmonary resuscitation was implemented according to the Japan Resuscitation Council Guidelines with a $0.5 \mathrm{mg}$ injection of atropine. Return of spontaneous circulation (ROSC) occurred about 2 minutes after the first cycle of cardiovascular resuscitation with an injection of $1 \mathrm{mg}$ adrenaline (Fig. 1).

The ECG was examined immediately after shifting the patient to the intensive-care unit. The ECG revealed STsegment elevation at II, III, and aVF (Fig. 2b). Echocardiography showed hypokinesia at the inferior wall. Therefore, acute inferior myocardial infarction (MI) was suspected; coronary angiography (CAG) and left ventriculography (LVG) were subsequently performed (Fig. 3). Although CAG did not reveal any abnormalities in coronary vessels, LVG showed a mid-ventricular pattern. The abnormalities in the ECG normalized the next day (Fig. 2c). Therefore, a mid-ventricular type of takotsubo cardiomyopathy was suspected of having occurred during the procedure. The patient was discharged seven days after this incident without any neurological symptoms.

A second ESD procedure was performed under general anesthesia using desflurane, remifentanil propofol, and rocuronium bromide 49 days after the cardiac arrest episode. There was no incidence of bradycardia or hypotension during the procedure. The lesion was removed completely. Moderate fibrosis was observed around the lesion due to the previous partial circumference. A histological examination showed that the lesion was well-differentiated tubular adenocarcinoma that had invaded within the intramucosal layer.

\section{Discussion}

Endoscopic procedures have become advanced and more complicated over the years, with the procedure time consequently lengthening. Conscious sedation is commonly used to reduce the pain, discomfort, and anxiety for patients and facilitate endoscopic procedures. Although propofol is a suitable medication for sedation (4), its usage has some limitations. The use of propofol is restricted to anesthesiologists in the United States, and an anesthesiologist's presence is required for its use in some countries, including Japan. DEX is a selective alpha- 2 adrenergic agonist that is used in anesthesia and some surgeries without intubation, such as endoscopic treatments and coronary artery interventions (1). The recommended amount of DEX for sedation of nonintubated patients is $1 \mu \mathrm{g} / \mathrm{kg}$ over 10 minutes as the loading dose and $0.6 \mu \mathrm{g} / \mathrm{kg} / \mathrm{h}$ (usually $0.2-0.7 \mu \mathrm{g} / \mathrm{kg} / \mathrm{h}$ ) for maintenance. These administration methods were approved by the Japanese health insurance system. Although the dosage for our patient met this recommendation, a lower dosage of DEX was administrated in some studies $(5,6)$. We should therefore use a reduced dosage at the start of procedures or in elderly patients. The Japanese guideline for sedation recommends the use of DEX for long endoscopic procedures (7). This means that DEX is not recommended to be used routinely. Therefore, we should use benzodiazepines and pentazocine at first and then consider adding DEX if sedation is not adequate or the procedure is prolonged, especially for elderly patients. This approach has the advantage of reducing respiratory depression.

The usefulness of DEX in endoscopic procedures has been reported $(8,9)$. Those studies found no severe complications due to DEX for ESD. Thus, DEX is widely used in endoscopic procedures. However, bradycardia and hypotension are occasionally experienced as side effects during the administration of DEX. The bradycardia and hypotension are generally managed by decreasing the infusion rate of DEX or stopping it altogether and by the administration of atropine. Although several cases of cardiac arrest due to 

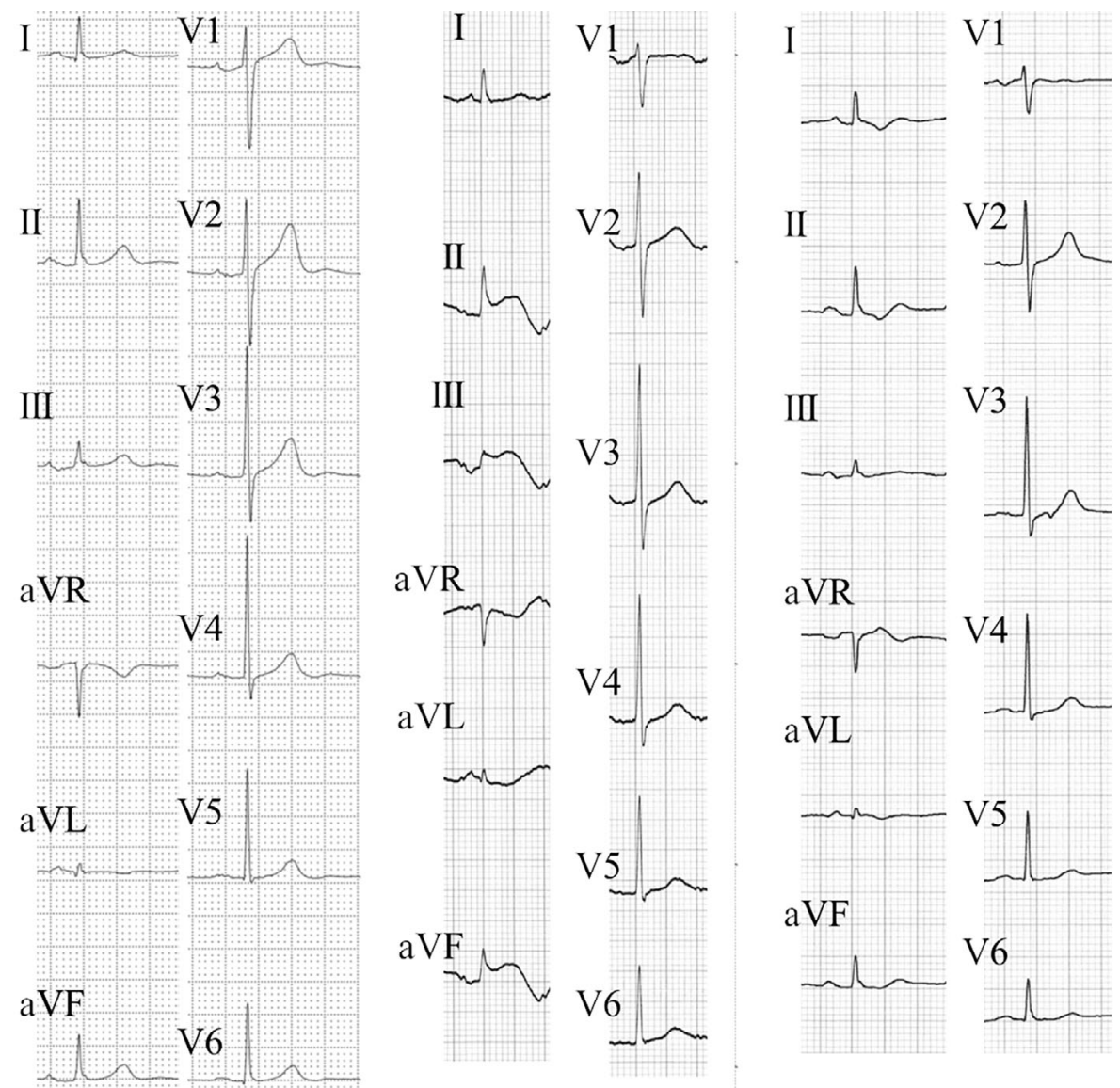

Figure 2. Electrocardiogram (ECG) findings. (A) An ECG before endoscopic submucosal dissection showed no abnormalities. (B) An ECG revealed ST segment elevation at II, III, and aVF immediately after resuscitation. (C) The ST segment elevations had improved the day after cardiac arrest.
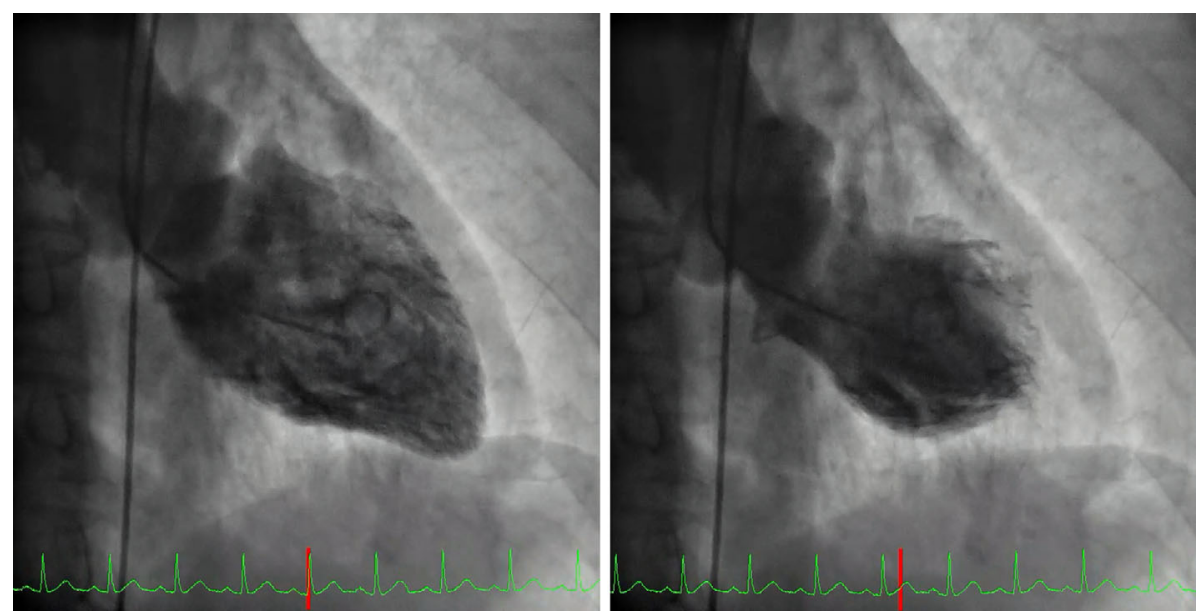

Figure 3. Left ventriculography (A: end diastole; B: end systole). A mid-ventricular pattern was suspected.

DEX have been reported (10-13), the patients in the reports usually had cardiovascular diseases, such as chronic heart failure or bundle branch block. To our knowledge, no cases of cardiac arrest-induced bradycardia by DEX during ESD have been reported. Furthermore, our patient did not have a history of cardiovascular diseases.

Cardiovascular complications associated with DEX are considered to be dose-dependent. Ebert et al. reported that a reduced cardiac function can increase the plasma concentrations of DEX (14). However, conversely, Takata et al. (12) argued that the concentration of DEX is not necessarily associated with the risk of cardiac arrest. However, since elderly patients may have cardiovascular dysfunction, we should consider reducing the infusion rate of DEX depend- 
ing on the age and complications of patients during procedures.

Although ROSC was obtained immediately, the ECG demonstrated ST-segment elevation. Thus, we initially suspected the involvement of an inferior MI. However, since the ST segment changes improved the next day, and the CAG showed no abnormality of coronary arteries, the possibility of MI was ruled out. Since LVG demonstrated a midventricular ballooning pattern, a mid-ventricular type of takotsubo cardiomyopathy was suspected of having occurred during a series of clinical procedures. Although the significance of takotsubo cardiomyopathy for the clinical course is uncertain, this could have been caused by significant emotional or physical stressors due to ESD, the bradycardia induced by DEX, and/or catecholamine administration during resuscitation (15).

Two incidents had the potential to induce cardiac arrest in our patient. One is takotsubo cardiomyopathy. However, while takotsubo cardiomyopathy has been reported to be a cause of cardiac arrest (16), we considered the cardiac arrest in our case to be due to the bradycardia that occurred as an adverse event of DEX, as the pulse rate decreased gradually, and cardiac arrest occurred without ST segment change. Furthermore, takotsubo cardiomyopathy has been reported to be induced by adrenaline injection (17). Another possibility is that the cardiac arrest was induced by other drugs. Midazolam and pentazocine were administrated to our patient before the cardiac arrest. However, while one case of cardiac arrest associated with pentazocine has been reported (18), it does not induce bradycardia, and the arrest caused by midazolam is usually associated with respiratory arrest (19), with the incidence of bradycardia also being very low (20). Therefore, we concluded that the cardiac arrest in our case was induced by DEX.

In conclusion, endoscopists should be aware that the use of DEX involves a risk of cardiac arrest during endoscopic procedures and be alert for bradycardia and hypotension that might occur during sedation with DEX.

The authors state that they have no Conflict of Interest (COI).

\section{Acknowledgement}

The authors would like to thank Dr. Abe and Dr. Akamatsu for their support of the patient in the intensive-care setting and for evaluating the cardiovascular condition.

\section{Author contributions}

Tomoaki Yamasaki examined the patient and wrote the article. Yuhei Sakata and Masafumi Yamamura examined the patient.

Takehisa Suekane and Hiroko Nebiki assisted in reporting the case.

\section{Disclosures}

All authors have no conflict of interest.

Human rights All procedures were performed in accordance with the ethical standards laid down in the 1964 Declaration of
Helsinki and its later amendments.

\section{Informed consent}

Written informed consent was obtained from the patients for being included in this report.

\section{References}

1. Gertler R, Brown HC, Mitchell DH, Silvius EN. Dexmedetomidine: A Novel Sedative-Analgesic Agent. Baylor Univ Med Cent Proc 14: 13-21, 2001.

2. Riker RR, Shehabi Y, Bokesch PM, et al. Dexmedetomidine vs Midazolam for Sedation of Critically Ill Patients: A Randomized Trial. JAMA 301: 489-499, 2009.

3. Jakob SM, Ruokonen E, Grounds RM, et al. Dexmedetomidine vs Midazolam or Propofol for Sedation During Prolonged Mechanical Ventilation: Two Randomized Controlled Trials. JAMA 307: 11511160, 2012.

4. Ominami M, Nagami Y, Shiba M, et al. Comparison of propofol with midazolam in endoscopic submucosal dissection for esophageal squamous cell carcinoma: a randomized controlled trial. J Gastroenterol 53: 397-406, 2018.

5. Muller S, Borowics SM, Fortis EAF, et al. Clinical efficacy of dexmedetomidine alone is less than propofol for conscious sedation during ERCP. Gastrointest Endosc 67: 651-659, 2008.

6. Kinugasa H, Higashi R, Miyahara K, et al. Dexmedetomidine for conscious sedation with colorectal endoscopic submucosal dissection: a prospective double-blind randomized controlled study. Clin Transl Gastroenterol 9: 167, 2018.

7. Gotoda T, Akamatsu T, Abe S, et al. Guidelines for sedation in gastroenterological endoscopy (second edition). Dig Endosc 33: 21-53, 2021.

8. Yoshio T, Ishiyama A, Tsuchida T, et al. Efficacy of novel sedation using the combination of dexmedetomidine and midazolam during endoscopic submucosal dissection for esophageal squamous cell carcinoma. Esophagus 16: 285-291, 2019.

9. Nishizawa T, Yahagi N. Long-term outcomes of using Endoscopic submucosal dissection to treat early gastric cancer. Gut Liver 119124, 2018.

10. Aikaterini A, Ioannis D, Dimitrios G, Konstantinos S, Vasilios G, George P. Bradycardia Leading to Asystole Following Dexmedetomidine Infusion during Cataract Surgery: DexmedetomidineInduced Asystole for Cataract Surgery. Case Rep Anesthesiol 2018: 2896032, 2018.

11. Kim BJ, Kim B Il, Byun SH, Kim E, Sung SY, Jung JY. Cardiac arrest in a patient with anterior fascicular block after administration of dexmedetomidine with spinal anesthesia A case report. Med (United States) 95: 2016.

12. Takata K, Adachi YU, Suzuki K, Obata Y, Sato S, Nishiwaki K. Dexmedetomidine-induced atrioventricular block followed by cardiac arrest during atrial pacing: A case report and review of the literature. J Anesth 28: 116-120, 2014.

13. Bharati S, Pal A, Biswas $C$, Biswas R. Incidence of cardiac arrest increases with the indiscriminate use of dexmedetomidine: A case series and review of published case reports. Acta Anaesthesiol Taiwanica 49: 165-167, 2011.

14. Ebert TJ, Hall JE, Barney JA, Uhrich TD, Colinco MD. The effects of increasing plasma concentrations of dexmedetomidine in humans. Anesthesiology 93: 382-394, 2000.

15. Amin HZ, Amin LZ, Pradipta A. Takotsubo Cardiomyopathy: A Brief Review. J Med Life 3-7, 2020.

16. Gili S, Cammann VL, Schlossbauer SA, et al. Cardiac arrest in takotsubo syndrome: results from the InterTAK Registry. Eur Heart J 40: 2142, 2019.

17. Maes S, Dhooghe NSJJ, Schotte H, Cattoir S, Jacobs TF, 
Van Landuyt K. Takotsubo Cardiomyopathy Induced by Epinephrine Infiltration for Liposuction. Broken Heart Syndrome 39: NP 431-NP436, 2019.

18. Kageyama S, Sasoh F, Taniguchi I, Homma I, Saito H, Isogai Y. Cardiorespiratory arrest in a patient with advanced diabetic autonomic neuropathy. Diabetes Res Clin Pract 1: 243-246, 1985.

19. Classen DC, Pestotnik SL, Evans RS, Burke JP. Intensive Surveillance of Midazolam Use in Hospitalized Patients and the Occurrence of Cardiorespiratory Arrest. Pharmacother J Hum Pharmacol
Drug Ther 12: 213-216, 1992.

20. Bellolio MF, Gilani WI, Barrionuevo P, et al. Incidence of Adverse Events in Adults Undergoing Procedural Sedation in the Emergency Department: A Systematic Review and Meta-analysis. Acad Emerg Med 23: 119, 2016.

The Internal Medicine is an Open Access journal distributed under the Creative Commons Attribution-NonCommercial-NoDerivatives 4.0 International License. To view the details of this license, please visit (https://creativecommons.org/licenses/ by-nc-nd/4.0/).

(C) The Japanese Society of Internal Medicine Intern Med Advance Publication 